\title{
Chronic pain in primary care. German figures from I 99 I and 2006
}

\author{
Christine H Frießem ${ }^{1}$, Anne Willweber-Strumpf ${ }^{2}$ and Michael W Zenz ${ }^{* 1,3}$
}

Address: ${ }^{1}$ Department of Anaesthesiology, Intensive Care, Palliative Care and Pain Medicine BG-Universitätsklinikum Bergmannsheil - University Hospital, Ruhr-University, Bochum, Germany, ${ }^{2}$ Pain clinic, Department of Anaesthesiology, Emergency and Intensive Care Medicine, Medical Centre University of Goettingen, Germany and ${ }^{3}$ Department of Anaesthesiology, Intensive Care and Pain Medicine Knappschaftskrankenhaus Langendreer - University Hospital, Ruhr-University, Bochum, Germany

Email: Christine H Frießem - friessem@anaesthesia.de; Anne Willweber-Strumpf - willweber@med.uni-goettingen.de; Michael W Zenz* - zenz@anaesthesia.de

* Corresponding author

Published: 18 August 2009

BMC Public Health 2009, 9:299 doi:10.1 I86/147|-2458-9-299
Received: 29 September 2008

Accepted: 18 August 2009

This article is available from: http://www.biomedcentral.com//47|-2458/9/299

(c) 2009 Frießem et al; licensee BioMed Central Ltd.

This is an Open Access article distributed under the terms of the Creative Commons Attribution License (http://creativecommons.org/licenses/by/2.0), which permits unrestricted use, distribution, and reproduction in any medium, provided the original work is properly cited.

\begin{abstract}
Background: Until now only limited research has been done on the prevalence of chronic pain in primary care. The aim of this investigation was to study the health care utilisation of patients suffering from pain. How many patients visit an outpatient clinic because of the symptom of pain? These data were compared with data from a similar study in 1991, to investigate whether improvements had been achieved.

Methods: A total of $120 \mathrm{I}$ consecutive patients visiting outpatient clinics were surveyed in six practices in the western part of Germany on randomly selected days by means of questionnaires. Topics were the point prevalence of pain and the period prevalence of chronic pain, its characteristics and its impact on daily life, as well as data on previous therapies for pain. A retrospective comparison was made with the data from a similar study with same design surveying 900 patients that took place in five practices during 1991.

Results: In 2006, pain was the main reason for consulting a doctor in $42.5 \%$ of all patients (1991: $50.3 \%$ ). Of all respondents, $62 \%$ suffered from pain on the particular day of the consultation, and $40 \%$ reported that they had been suffering from pain for more than six months (1991: $36.4 \%$ ). As many as $88.3 \%$ of patients with chronic pain reported a negative impact on their daily life due to this pain (1991: 68\%), and $88.1 \%$ reported impairment of their working life because of chronic pain (1991: 59.1\%).

Conclusion: Pain, and chronic pain in particular, is a central problem in primary care. Over the last 15 years, the number of patients suffering from chronic pain has not decreased. In nearly half of all cases, pain is still the reason for health care utilisation in outpatient clinics. Pain represents a major primary health care problem with enormous impact on public health. Improvements can only be achieved by improving the quality of health care at the primary care level.
\end{abstract}




\section{Background}

It is estimated that at least 8 to 10 million patients in Germany (around 10\% of the population) suffer from chronic pain. Approximately 500000 to 800000 patients have difficult and complex pain problems demanding specialist treatment [1].

In the last few years, several epidemiological studies have been carried out. It is difficult to draw any reliable conclusions on the course and development of chronic pain in the outpatient care system. The direct comparison of study results over the years is hampered by heterogeneous populations, and by differences in sample sizes, randomisation techniques, methods, definitions of chronic pain and different estimates for prevalence levels. Consequently, data have revealed significant method-specific differences in the prevalence of chronic pain.

Epidemiological population-based studies report a pain prevalence of between $2 \%$ and $46.5 \%$ depending on the investigation and definition [2-6]. Interviews in the practices of both general practitioners (GPs) and specialists have indicated a variable and higher prevalence of between 22\% and 50.4\% [3,7-9]. Pain has become the most prevalent symptom in patients seeking medical advice, and is one of the main issues in public health $[10,11]$.

Fifteen years after the first investigation [9], a similar study was designed and carried out in primary care in the same area of Germany. So the two data sets are really comparable and give hints as to changes. The aim of this study was to demonstrate the actual primary care utilisation of patients suffering from pain as the leading symptom. Additionally, the investigation aimed to look at trends over time and to demonstrate possible improvements in the outpatient care of pain patients resulting from the effort and actions of national and international pain societies.

\section{Methods \\ Collection of epidemiological data}

At the beginning of 2006, six different practices in Bochum were selected as representative of the different disciplines for the diagnosis and treatment of pain (general medicine with a focus on homoeopathy, surgery, internal medicine, neurology, oncology and orthopaedics). Upon approval of the ethics committee of the Medical Faculty of the Ruhr University Bochum, on randomly selected days all consecutive patients of all age groups entering these practices were asked to participate. Exclusion criteria were poor health, concerns about privacy and inability to understand the German questionnaire. It was planned to include up to 200 patients from each practice.
General information about the survey was provided by a flyer distributed at the reception desk. In the waiting room, all patients were informed about the aim and purpose of the survey and how to fill in the questionnaire. Once they had given their consent, patients were asked to complete the self-administered questionnaire. In cases of difficulty in understanding a question, assistance was provided by the same person, who had a medical background. All questionnaires were anonymous.

An investigation featuring the same study design had already been carried out in 1991 [9,12], and the same practices were used in the second investigation. In addition, the practice of a specialist in oncology was added in 2006, to include the aspect of cancer pain. In order to ensure comparability of the data of both investigations, the 2006 questionnaire was identical to the previous one [12]. By this means, prospective data from 2006 and retrospective data from 1991 could be compared.

\section{Structure of questionnaire}

The questionnaire consisted of two different parts. [Additional file 1]. Part A collected demographic and social data and was answered by all patients who agreed to participate. Point prevalence of pain was revealed with the question: Do you suffer from pain today? Part B was only answered by those patients who suffered from chronic pain - irrespective of whether pain was the reason for the current visit to the doctor representing a period prevalence. Detailed data (Part B) were obtained if pain was the primary or secondary reason for the visit to the doctor. Chronic pain was defined as recurring or constant pain lasting longer than six months [13-17]. Acute pain was defined as pain lasting for hours or days.

The denominators of the data collected in Part B included only patients who reported chronic pain. This part of the questionnaire contained the characteristics, duration and localisation of the pain. The intensity of pain was reported by means of an eleven-point numerical rating scale (NRS) ranging from 0 to $10(0=$ no pain, $10=$ worst possible pain). Using multiple-choice questions, patients were asked about the impact of pain on their daily activities, sleep and respective employment status. Other questions dealt with previous therapies and their subjective effects. The questionnaire included two open questions about profession and diagnosis as well as multiple-choice questions. Multiple answers were allowed for certain questions (for example, pain location, previous therapies and their subjective effects, and the daily impact of chronic pain).

\section{Statistical evaluation}

Statistical differences between the results of 1991 and 2006 were calculated by means of the chi-square cross tab- 
ulation test, using the statistical software StatView Version 5.0 for Macintosh and Windows. Statistical significance was considered at $\mathrm{p}<0.05$.

\section{Results}

In this section all results from 2006 are presented. For clear discrimination the figures from 1991 together with the significances are given in brackets following.

\section{Demographic aspects}

In total 1201 questionnaires were completed $(\mathrm{N}=1201)$ except for a limited number of questions $(1991: \mathrm{n}=900)$. The refusal rate was $4.61 \%$. The reason for exclusion was not always given. Only two patients were excluded because of poor health conditions. Both were not suffering from acute or chronic pain. Most of the excluded cases were related to the Turkish societies having difficulties with the German questionnaire. Women answered $61.7 \%$ of the questionnaires (1991: 60\%). The mean age of all respondents was 53.4 years (1991: 48.6 years). The mean age of patients suffering from pain was 58.4 years. [Table $1]$.

\section{Social data}

More than half of the patients (55.6\%) suffering from chronic pain were married (1991: 57\%) and $9.4 \%$ of respondents with chronic pain were divorced (1991: $6.7 \%$ ). Of the chronic pain sufferers, $43.6 \%$ had a general certificate of secondary education (grade 9 at any secondary school; 1991 : $56.3 \%$; $=0.0005$ ) while $23.5 \%$ of them had Abitur (corresponding to A-levels; 1991: $17.8 \%$ ). The open question about profession could not be analysed because of missing answers. It was excluded to guarantee full comparability between the two questionnaires.

\section{Prevalence of pain}

Pain was the main reason for the visit to the outpatient clinic in $42.5 \%$ of all participating patients in 2006 (1991: $50.3 \% ; \mathrm{p}=0.0003$ ). A total of $62 \%$ of respondents suffered from acute or chronic pain on the day of the survey $2006(1991: 61.7 \%) .40 \%\left(\mathrm{n}_{2006}=480\right)$ suffered from chronic pain (1991: 36.4\%; $\mathrm{n}_{1991}=328$ ). The greatest numbers of patients with chronic pain were seen in the general practice, with 50\% (1991: 28\%; $\mathrm{p}<0.0001$ ), and the fewest were seen in the surgical practice, with $32 \%$ (1991: $14 \% ; p<0.0001$ ). In the oncology practice, $38.3 \%$ of all patients had chronic pain. Of all patients, $22.1 \%$ suffered from acute pain (1991: 25.3\%). In both survey years, women suffered from chronic pain twice as often as men. [Table 1]. The open question about pain diagnosis could not be analysed because of missing answers. Further

Table I: Basic data: Comparison of the surveys of 199 I and 2006

\begin{tabular}{lcc}
\hline & 1991 & 2006 \\
\hline Number of practices $(\mathrm{n})$ & 5 & 6 \\
\hline Number of patients (N) & 900 & 1201 \\
\hline women (n/\%) & $540 / 59.9$ & $741 / 61.7$ \\
\hline men (n/\%) & $360 / 40.1$ & $460 / 38.3$ \\
\hline mean age total (in years) & 48.6 & 53.4 \\
\hline Patients with acute pain (n/\%) & $228 / 25.3$ & $265 / 22.1$ \\
\hline Patients with chronic pain (n/\%) & $328 / 36.4$ & $480 / 40.0$ \\
\hline women (n/\%) & $219 / 66.8$ & $324 / 67.5$ \\
\hline men (n/\%) & $109 / 33.2$ & $156 / 32.5$ \\
\hline mean age total (in years) & - & 58.4 \\
\hline Actual consultation due to pain (n/\%) & $453 / 50.3 * *$ & $510 / 42,5 * *$ \\
\hline Actual consultation due to acute pain (n/\%) & $228 / 25.3 * *$ & $227 / 18.9 * *$ \\
\hline Actual consultation due to chronic pain (n/\%) & $225 / 25.0$ & $283 / 23.6$ \\
\hline
\end{tabular}

- missing data; $* * p<0.001$ 
results of the individual specialists' offices will be presented in a separate paper.

\section{Characteristics of chronic pain}

The most frequent type of pain was musculoskeletal pain. The main locations of pain were back in 59.4\% (1991: $53.4 \%$ ) and joints in 33.1\% (1991: 28.0\%). Only $14.9 \%$ complained of headache (1991: 29.3\%; p < 0.0001). [Fig. 1].

The number of patients suffering pain for more than five years was as high as 67.5\% (1991: 51.5\%; p < 0.0001), while $26 \%$ of patients recorded pain lasting longer than 20 years (1991: $16.7 \% ; \mathrm{p}=0.0015$ ).

A total of $73.2 \%$ of chronic pain sufferers estimated the intensity of their chronic pain to be between 6 and 10 on the numeric rating scale (NRS 0-10; 1991: 34.1\%).

In both time periods, the factors most frequently activating chronic pain were physical strain in $72.6 \%$ (1991: $65.4 \%$; $\mathrm{p}<0.0001$ ), weather conditions in $41 \%$ (1991: $49.4 \% ; \mathrm{p}=0.0208)$ and psychological strain in $34.5 \%$ (1991: 36.9\%).

The open question about the pain-causing diagnosis could not be analyzed due to missing answers.

Among own efforts at relieving pain, analgesic medication was considered the best method by $65 \%$ of the respondents (1991: 52.7\%; $\mathrm{p}=0.0005$ ). [Fig. 2].

\section{Effects of chronic pain}

Impairment in everyday life caused by chronic pain was felt significantly more strongly than 15 years earlier. This became especially apparent during leisure in $63.1 \%$ (1991: 43.9\%; $\mathrm{p}<0.0001$ ), housekeeping in 54\% (1991: $16.8 \% ; \mathrm{p}<0.0001)$ and personal hygiene activities in 19\% (1991: 5.5\%; $\mathrm{p}<0.0001$ ). In $14.3 \%$ of the patients, workdays were lost because of their chronic pain (1991: $19.2 \%)$. Only $11.7 \%$ did not feel any impairment from their chronic pain (1991: 32\%; p < 0.0001). [Fig. 3].

Chronic pain had negative effects on the sleep of $66.3 \%$ of the patients (1991: $70.1 \%$ ), and $24.8 \%$ were on sleeping pills because pain affected their sleep so much (1991: $34.8 \%)$.

\section{Previous therapies and their subjective effects}

Only $6.3 \%$ of respondents with chronic pain had not yet had any specific pain treatment. The frequency of consulting a pain specialist had increased to $11.3 \%$ in 2006 (1991: 0.9\%; $\mathrm{p}<0.0001$ ).

The methods used for pain therapy had increased: medication in 69.8\% (1991: 51.2; p < 0.0001), injections in 51.2\% (1991: 39.6\%; p < 0.0001), acupuncture in $49.7 \%$ (1991: 5.8\%; $\mathrm{p}<0.0001$ ) and operations in 21.2\% (1991: 9.5\%; $\mathrm{p}<0.0001$ ) were used against pain.

Medication was considered to be the most effective method in 34.4\% (1991: 25.9\%; $\mathrm{p}=0.107$ ), while $18.8 \%$

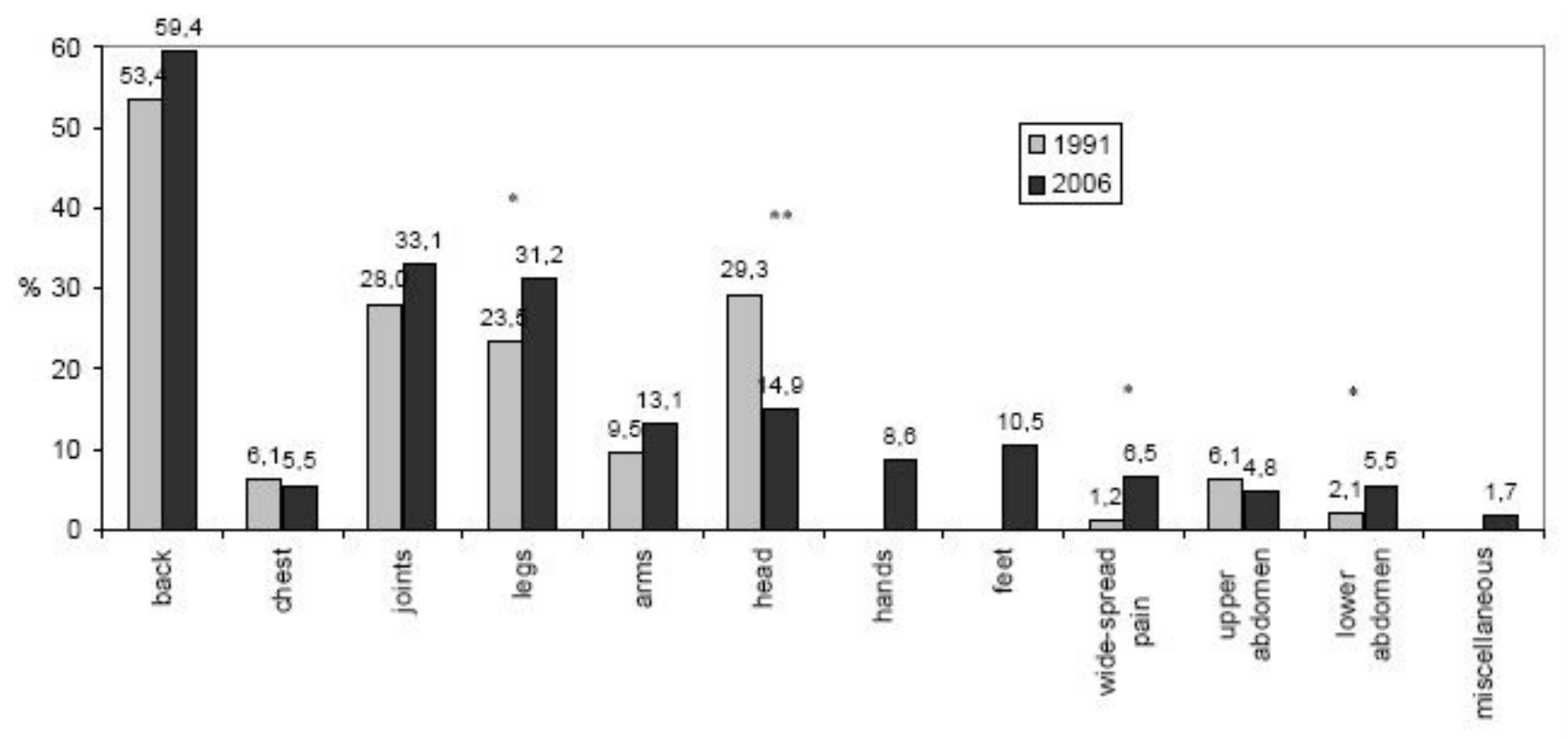

Figure I

Distribution of bodily locations of chronic pain in 1991 and 2006 (\%). Multiple answers allowed, nI99I = 328, n2006 = $475 *_{p}<0.05, * *_{p}<0.001$. 


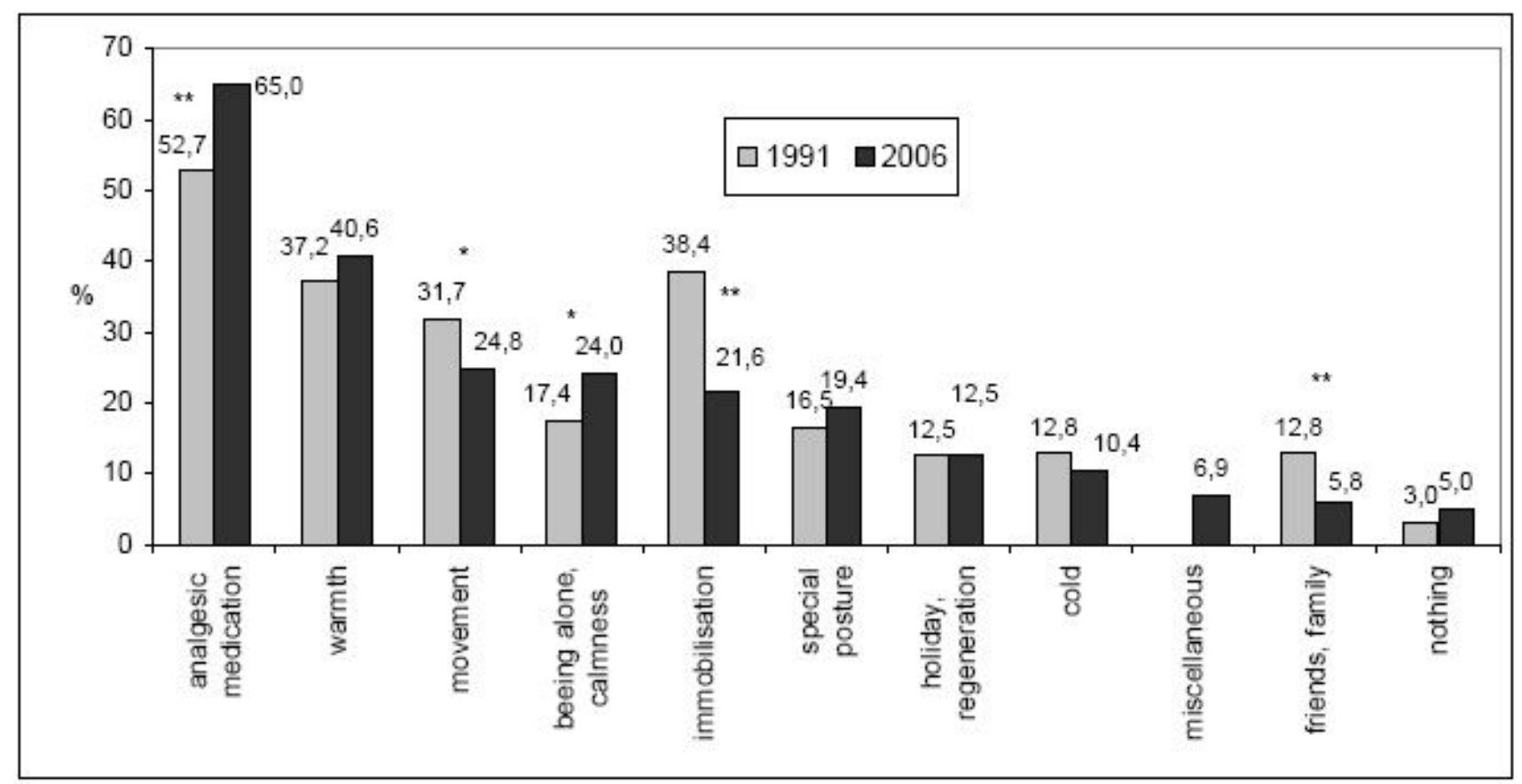

Figure 2

Most helpful measures at relieving chronic pain (\%). Multiple answers allowed, $n 1991=328, n 2006=463 * p<0.05$; **p $<0.001$.

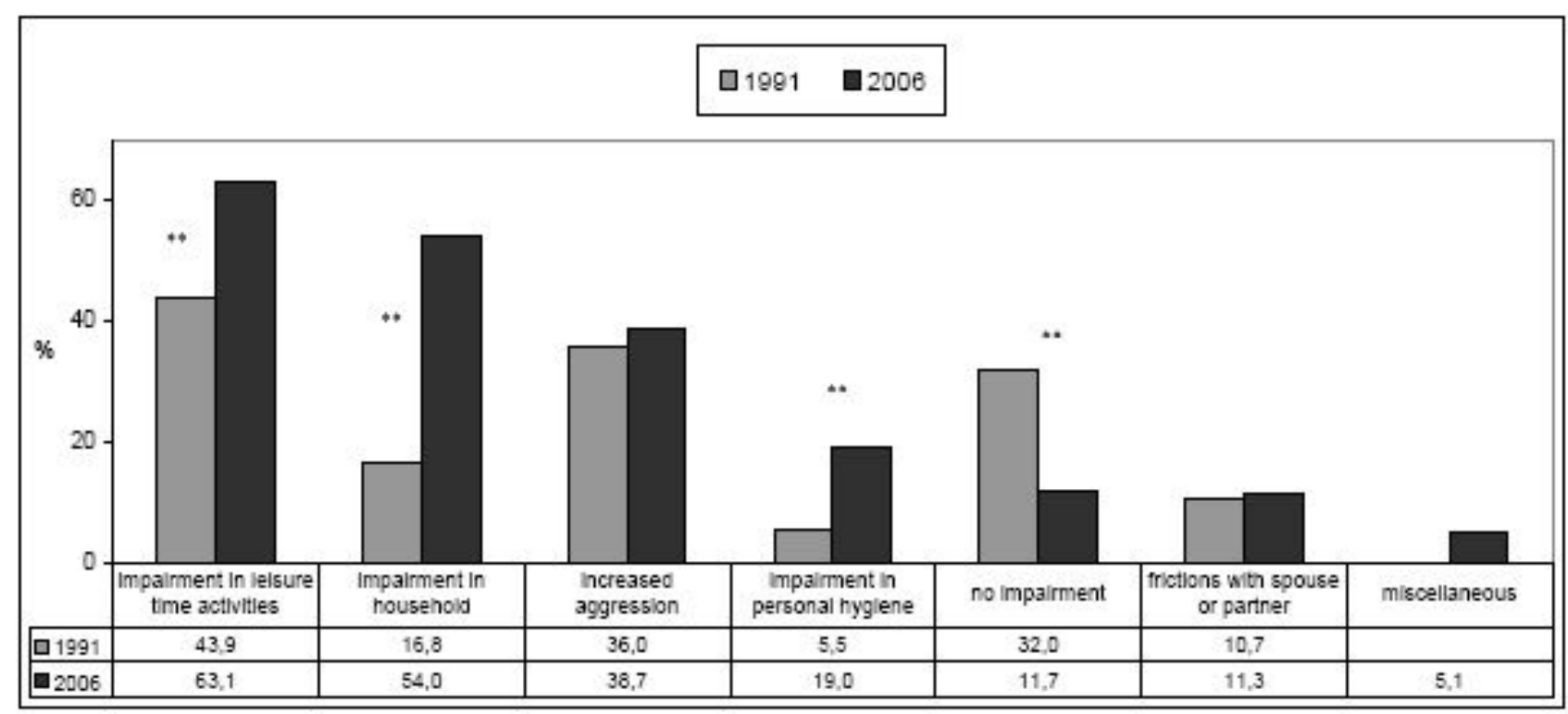

Figure 3

Impairment of daily activities by chronic pain (\%). Multiple answers allowed, $n / 99$ I $=328, n 2006=452 * p<0.05, * * p<$ 0.001 . 
considered physiotherapy an efficient treatment (1991: $8.8 \%$; $\mathrm{p}<0.0001), 17.7 \%$ obtained pain relief from acupuncture (1991: $3.6 \%$; $<<0.0001$ ), and $24.7 \%$ of the patients did not consider any of these methods an efficient way of relieving pain (1991: 29.3\%).

\section{Discussion}

This study is the first to directly compare data on the changes in pain prevalence on randomly selected days in a comparable population in primary care, focussing on pain as the reason for outpatient health care visits. The investigation was designed as an independent, unselected random sample of outpatient health care users following the same model as in the first survey carried out in 1991 $[9,12]$.

The point prevalence was unchanged from 15 years ago. Nearly every second patient consulted a primary care physician because of pain, and every fourth patient visited a doctor because of long-lasting pain. These figures illustrate the pain sufferer's high need for proper diagnosis and treatment.

In the last 15 years, the possibilities for pain treatment have definitely improved in Germany, both with regard to therapy options and the number of pain specialists. The period prevalence of chronic pain lasting longer than six months, however, has not decreased accordingly. Within these 15 years a significant improvement - a decrease in chronic pain - was expected. In these years the number of pain specialists and interdisciplinary pain clinics in Germany increased considerably $[18,19]$. The specialisation "special pain therapy" was introduced in 1996, bringing the first specialisation worldwide. However, these improvements, as well as the facilitation of pain therapy by the amendment of opioid regulations have obviously had no positive impact on the prevalence of chronic pain. Obviously, competence in diagnosis and treatment of pain has not changed.

The city of Bochum, with 380000 inhabitants is an urban area in western Germany. All patients in Germany are primarily diagnosed and treated by their home physicians. It is up to the patient to decide which physician to use as a home physician. Patients can select any outpatient clinic for their home physician (general practitioner, neurologist, surgeon, internist), but the primary care consultation always takes place with one of these home physicians. Different practices were chosen during the investigations to include a wide spectrum of possible consultations for pain. Therefore our figures give a fairly exact picture of pain in primary care.

Our results are supported by previous and current studies. In collected data from Finland, the point prevalence of patients consulting a general practitioner due to pain was
$40 \%$ [20]. Also a report from the USA indicated that more than one-third of adult appointments in a typical week in primary care involved patients with complaints of chronic pain [21].

There are no studies investigating trends of point prevalence of pain among health care users. The period prevalence of pain complaints was found to be stable in the adult Danish population over a five-year period [22]. However, the point prevalence of specific musculoskeletal pain symptoms over 40 years in the British population increased about 2- to 4-fold [23].

Among other possible reasons, this could be explained by an increase in the reporting or awareness of pain as the leading symptom. The number of pain patients is expected to rise. The demographic changes in industrial countries alone account for the increased average age of all patients in the study. Patients suffering from long-lasting pain are ten years older than those suffering from acute pain or those without pain. Age is one predisposing factor for chronic pain. Increasingly, "pain in the elderly" plays an important role in public discussions $[24,25]$.

\section{Limitations}

To simplify the realisation of this survey, a one-dimensional definition of chronic pain by duration has been chosen. Certainly a multidimensional definition of pain would cover the pain problem better [26]. However, such a multidimensional approach is difficult in the mixed patient population and in the busy environment of primary care. Most importantly, in our study the main focus was pain as a symptom for which to seek primary care.

Data from open questions were excluded to guarantee comparability. Lack of answers led to insufficient data. It is assumed that the missing replies about profession were an issue of privacy and those about pain diagnosis were due to nescience.

We did not study the doctors' records. Medical consultation records instead of our surveys would give a false negative picture of the pain problem, because pain diagnoses very seldom occur. The International Classification of Diseases (ICD) still has no specific diagnosis for chronic pain. Pain occurs as angina pectoris, persistent somatoform disorder or trigeminal neuralgia [27]. Related to the ICD, pain is a minor health problem, because it is summarised under somatic disorders with the symptom of pain. This understanding contrasts with the modern view of pain as an illness on its own [28].

The inclusion of an oncology practice did not change the balance by increasing the pain prevalence. We have included these patients, because a criticism of our initial 
paper was the fact that cancer patients were omitted. It was suspected that this absence of cancer patients would have decreased the total prevalence. Surprisingly, fewer patients in oncology consulted the doctor due to pain. In the actual data from 2006 this assumption is not justified, as our figures demonstrate. We believe that comparability between the two studies was also provided by the inclusion of cancer patients.

The most prominent pain problem remains back pain, where simple diagnostic and therapeutic tools are neglected [4,29-31]. Pain in the musculoskeletal system is the main symptom for seeking a consultation with a primary care physician [32].

Our random sample has revealed that, in particular, patients who are unemployed, divorced or who left school after grade 9 have a greater tendency to suffer from chronic pain. Similar results have been published [33,34]. Such social parameters reflect the general development in modern societies. More people have reached higher education levels, and the divorce rate in Germany has increased from $30 \%$ to over 50\% [35].

Pain had a considerable impact on the daily life of the patients concerned. The fact that $90 \%$ see themselves as impaired in their daily activities illustrates the extent of the restrictions due to pain. Emotional changes due to pain lead to high psychological strain and loss of quality of life [36]. In addition, there are severe consequences to be considered from a (socio-) economic point of view [3739]. Nowadays, $90 \%$ of pain sufferers experience impairment of their jobs. Despite their pain, more people actually continued to go to work [40]. It can be anticipated that work efficiency is impaired by chronic pain, and this might be as important as the loss of working days [41]. Therefore, countrywide provision of multimodal pain therapy is needed [42], as well as effective early pain diagnosis for the prevention of chronic pain. The costs of both solutions have proven to be lower than the potential follow-up costs of a chronic pain disease or the costs of absenteeism and early retirement $[2,39,43]$. Only then it will be possible to take the pressure off the health care system in years to come.

These days pain causes more severe complaints and interferences. This assumption is supported by the fact that patients frequently complained of the psychosocial impacts of their chronic pain. Many patients with chronic pain continue working due to the increased pressure of the actual job market. The German health report presents fewer sickness leaves in the last decade [44]. Interestingly pain has not been mentioned as a symptom or as an illness in the German health report. Facing the fact that nearly every second patient makes use of primary care due to a pain problem underlines the need to make pain as an illness and a health problem more visible. Moreover, there is possibly an indeterminate number of patients who do not consult a doctor because of fear of unemployment.

The average duration of pain in chronic pain sufferers was 10.7 years [17]. Patients fail to receive adequate diagnosis and treatment of pain in primary care, before they attend a specialist after too many years of mismanagement [45]. Consequently, psychological therapies, medication and alternative techniques are now used more often. This increased need for different treatment approaches and the rising number of patients suffering from intense pain could be explained by a higher degree of chronic suffering over the last decade. Longitudinal studies confirm this observation $[46,47]$. However, the increased use of different approaches does not result in improved pain relief, as the respondents considered single measures rather ineffective. Every fourth pain patient is displeased with the effect of therapy, which is a slight improvement compared to our previous results $[9,12]$. The rate of pain treatment success is low, and confounding factors - psychological and social - contribute to a purely somatic picture of pain [7]. Awareness of non-somatic factors is important to avoid chronification.

However, only a few patients have received pain treatment properly adjusted to their needs. Less than $24.7 \%$ of patients consider any of their therapies satisfactory in reducing their chronic pain [48]. Surprisingly, neither a pain clinic nor pain specialists were able to fully meet their needs.

In our study, only a few patients who visited the practices were unwilling to take part and were excluded. The personal contact in the practice waiting rooms may have been of help, as the rate of refusal was far lower than in other pain prevalence investigations using telephone interviews or postal questionnaires, where the rates of refusal were $29.2 \%$ and $64.1 \%$, respectively $[49,50]$.

Pain plays a central role in the health care system, and is one of the most frequent reasons for consulting a doctor. There is a strong association between pain and the greater use of health care services [51,52]. Primary care is the most frequent care provider for pain [53]. However, most health care systems are not sufficiently prepared to meet these demands. If this fundamental problem is not solved, the process of chronification of pain proceeds. To distinguish pain as an illness on its own, a careful diagnosis is essential $[28,54]$. 
A solution to the continuing problem of chronic pain is only a careful undergraduate and postgraduate training in pain diagnosis and treatment $[6,55]$. Pain as a major health problem - possibly the major health problem - is still not obligatory in undergraduate training in Germany.

\section{Conclusion}

Pain is the reason for primary health care utilisation in nearly half of all cases. The family doctor plays a key role, being the first contact person for the patient [3], and the most important one for preventing the chronification of pain. Also, for family physicians, a multidimensional approach is required to address the problem in the community [56]. The treatment of pain usually comes too late. Prevention of chronic pain is the central issue, and improvement can only be made by improving quality at the primary care level. Our figures demonstrate that there is still a huge deficit in this area of care.

\section{Competing interests}

The authors declare that they have no competing interests.

\section{Authors' contributions}

CHF was the principal investigator, attended the questionnaire survey, did the statistical analyses, and drafted the manuscript. AWS contributed to the statistical analyses and participated in the drafting of the manuscript. MWZ was responsible for the concept, made a critical revision of the manuscript. All authors have read and approved the final manuscript.

\section{Additional material}

\section{Additional file 1}

German Questionnaire. The file provides the German questionnaire used in this study.

Click here for file

[http://www.biomedcentral.com/content/supplementary/1471-

2458-9-299-S1.pdf]

\section{References}

I. German Bundestag: Antwort der Bundesregierung auf die kleine Anfrage Abgeordneter - Adäquate Versorgung von Schmerzpatienten Printed paper 2003, 15:2295 [http://dip21.bun destag.de/dip2I/btd/I5/022/I502295.pdf].

2. Breivik H, Collett B, Ventafridda V, Cohen R, Gallacher D: Survey of chronic pain in Europe: prevalence, impact on daily life, and treatment. Eur J Pain 2006, 10:287-333.

3. Elliott AM, Smith BH, Penny KI, Smith WC, Chambers WA: The epidemiology of chronic pain in the community. Lancet 1999, 354: | 248- 1252.

4. Nickel R, Raspe HH: Chronic pain: epidemiology and health care utilization. Nervenarzt 2001, 72:897-906.

5. Verhaak PF, Kerssens JJ, Dekker J, Sorbi MJ, Bensing JM: Prevalence of chronic benign pain disorder among adults: a review of the literature. Pain 1998, 77:231-239.

6. Neville A, Peleg R, Singer Y, Sherf M, Shvartzman P: Chronic pain: a population-based study. Isr Med Assoc J 2008, I 0:676-680.
7. Gureje O, Von Korff M, Simon GE, Gater R: Persistent pain and well-being: a World Health Organization Study in Primary Care. Jama 1998, 280:|47-I5I.

8. Hasselstrom J, Liu-Palmgren J, Rasjo-Wraak G: Prevalence of pain in general practice. Eur J Pain 2002, 6:375-385.

9. Willweber-Strumpf A, Zenz M, Bartz D: Epidemiology of Chronic pain - an investigation in $\mathbf{5}$ medical practices. Schmerz 2000, | 4:84-9|.

10. Catala E, Reig E, Artes M, Aliaga L, Lopez JS, Segu JL: Prevalence of pain in the Spanish population: telephone survey in $\mathbf{5 0 0 0}$ homes. Eur J Pain 2002, 6: I33-I40.

II. Von Korff M, Wagner EH, Dworkin SF: Chronic pain and use of ambulatory health care. Psychosom Med I99I, 53:6I-79.

12. Bartz D: Chronische Schmerzen im hausärztlichen Bereich: Eine Befragung in fünf Bochumer Facharztpraxen. In PhD thesis Ruhr-University Bochum, Faculty of medicine; 1999.

13. Von Korff M, Dworkin SF, Resche LL, Kruger A: An epidemiologic comparison of pain complaints. Pain 1988, 32:173-183.

14. Potter RG, Jones JM: The evolution of chronic pain among patients with musculoskeletal problems: a pilot study in primary care. Br J Gen Pract 1992, 42:462-464.

I5. Eriksen J, Jensen MK, Sjogren P, Ekholm O, Rasmussen NK: Epidemiology of chronic non-malignant pain in Denmark. Pain 2003, 106:221-228.

16. Brattberg G, Thorslund M, Wikman A: The prevalence of pain in a general population. The results of a postal survey in a county of Sweden. Pain 1989, 37:215-222.

17. Moulin DE, Clark AJ, Speechley M, Morley-Forster PK: Chronic pain in Canada - prevalence, treatment, impact and the role of opioid analgesia. Pain Res Manag 2002, 7:I79-184.

18. Kayser H, Thoma R, Mertens E, Sorgatz H, Zenz M, Lindena G: Structure of outpatient pain therapy in Germany. Results of a survey. Schmerz 2008, 22:424-432.

19. Lindena G, Hildebrandt J, Diener HC, Schops P, Maier C: Pain treatment facilities in Germany. Ambulatory, day care and inpatient facilities for patients with chronic pain. Schmerz 2004, 18:10-16.

20. Mäntyselkä P, Kumpusalo E, Ahonen R, Kumpusalo A, Kauhanen J, Viinamaki $H$, Halonen $P$, Takala J: Pain as a reason to visit the doctor: a study in Finnish primary health care. Pain 200I, 89: $175-180$.

21. Upshur CC, Luckmann RS, Savageau JA: Primary care provider concerns about management of chronic pain in community clinic populations. J Gen Intern Med 2006, 2 I :652-655.

22. Sjogren P, Ekholm O, Peuckmann V, Gronbaek M: Epidemiology of chronic pain in Denmark: an update. Eur J Pain 2009, I 3:287-292.

23. Harkness EF, Macfarlane GJ, Silman AJ, McBeth J: Is musculoskeletal pain more common now than $\mathbf{4 0}$ years ago?: Two population-based cross-sectional studies. Rheumatology (Oxford) 2005, 44:890-895.

24. Gibson SJ: IASP global year against pain in older persons: highlighting the current status and future perspectives in geriatric pain. Expert Rev Neurother 2007, 7:627-635.

25. International Association for the Study of Pain [http:www.iasp-pain.org/AM/Template.cfm?Sec tion=Resources\&Template $=/ C M /$ ContentDisplay.cfm\&Conten tID=36II]

26. Von Korff M, Dunn KM: Chronic pain reconsidered. Pain 2008, I38:267-276.

27. World Health Organization: ICD [http://www.WHO.int/classi fications/apps/icd/icd I0online]

28. Niv D, Devor M: Chronic pain as a disease in its own right. Pain Pract 2004, 4: I79-18I.

29. Bellach BM, Ellert U, Radoschewski : Epidemiologie des Schmerzes- Ergebnisse des Bundes-Gesundheitssurveys 1998. Gesundheitsforsch- Gesundheitsschutz 2000, 43:424-43I.

30. Kohlmann T: Pain complaints among inhabitants of Lubeck: results of a population-based epidemiologic study. Schmerz |99|, 5:208-2|3.

31. Kinkade S: Evaluation and treatment of acute low back pain. Am Fam Physician 2007, 75: I I8I-I I88.

32. Uhlig $\mathrm{T}$, Hagen KB, Kvien TK: Why do patients with chronic musculoskeletal disorders consult their primary care physicians? Curr Opin Rheumatol 2002, 14:104-108.

33. Schumacher J, Brähler E: The prevalence of pain in the German population: results of population-based studies with the 
Giessen Subjective Complaints List (Giessener Beschwerdebogen GBB). Schmerz 1999, I 3:375-384.

34. Yu HY, Tang Fl, Kuo Bl, Yu S: Prevalence, interference, and risk factors for chronic pain among Taiwanese community older people. Pain Manag Nurs 2006, 7:2-II.

35. Statistisches Bundesamt [http://www.destatis.de/jetspeed/por tal/cms/Sites/destatis/Internet/DE/Conte nt/Publikationen/Querh nittsveroeffentlichungen/WirtschaftStatistik/Bevoelk erunescheidungen05,property=file.pdf]

36. Wang HM, Beyer M, Gensichen J, Gerlach FM: Health-related quality of life among general practice patients with differing chronic diseases in Germany: cross sectional survey. BMC Public Health 2008, 8:246.

37. Göbel $H$ : Epidemiology and costs of chronic pain syndromes exemplified by specific and unspecific low back pain. Schmerz 200I, 15:92-98.

38. Sleed M, Eccleston C, Beecham J, Knapp M, Jordan A: The economic impact of chronic pain in adolescence: methodological considerations and a preliminary costs-of-illness study. Pain 2005, I 19:183-190.

39. Stewart WF, Ricci JA, Chee E, Morganstein D, Lipton R: Lost productive time and cost due to common pain conditions in the US workforce. Jama 2003, 290:2443-2454.

40. Council S: Reports from the Swedish Council on Technology Assessment in Health Care. Back pain. Int J Technol Assess Health Care 2000, 16:929-943.

4I. Blyth FM, March LM, Nicholas MK, Cousins MJ: Chronic pain, work performance and litigation. Pain 2003, 103:4I-47.

42. Lang E, Kastner S, Liebig K, Neundorfer B: Interventions for improvement of primary care in patients with low back pain: how effective are advice to primary care physicians on therapies and a multimodal therapy program arising out of cooperation of outpatient health care structures? Schmerz 2002, 16:22-33.

43. Strumpf $M$, Willweber-Strumpf $A$, Zenz M: Economic aspects of pain therapy. Z Ärztl Fortbild Qualitätssich 1998, 92:65-69.

44. Robert-Koch-Institut Fhr: Health in Germany. In Health in Germany Robert Koch Institute; Germany; 2008.

45. Strumpf M, Zenz M, Willweber-Strumpf A: Analysis of the therapy of chronic pain. A comparison of previous therapy and specialized pain therapy. Anaesthesist 1993, 42:169-174.

46. Bergman S, Herrstrom P, Jacobsson LT, Petersson IF: Chronic widespread pain: a three year followup of pain distribution and risk factors. J Rheumatol 2002, 29:8I 8-825.

47. Elliott AM, Smith BH, Hannaford PC, Smith WC, Chambers WA: The course of chronic pain in the community: results of a 4-year follow-up study. Pain 2002, 99:299-307.

48. Watkins EA, Wollan PC, Melton LJ 3rd, Yawn BP: A population in pain: report from the Olmsted County health study. Pain Med 2008, 9:166-174.

49. Blyth FM, March LM, Brnabic AJ, Jorm LR, Williamson M, Cousins MJ: Chronic pain in Australia: a prevalence study. Pain 2001 , 89:127-134

50. Mallen C, Peat G, Thomas E, Croft P: Severely disabling chronic pain in young adults: prevalence from a population-based postal survey in North Staffordshire. BMC Musculoskelet Disord 2005, 6:42.

5I. Blyth FM, March LM, Brnabic AJ, Cousins MJ: Chronic pain and frequent use of health care. Pain 2004, I I I:5 I-58.

52. Buskila D, Abramov G, Biton A, Neumann L: The prevalence of pain complaints in a general population in Israel and its implications for utilization of health services. / Rheumatol 2000 , 27:152I-I525.

53. Andersson HI, Ejlertsson G, Leden I, Schersten B: Impact of chronic pain on health care seeking, self care, and medication. Results from a population-based Swedish study. J Epidemiol Community Health 1999, 53:503-509.

54. Niv D, Devor M: Position paper of the European Federation of IASP Chapters (EFIC) on the subject of pain management. Eur J Pain 2007, I I:487-489.

55. Stannard C, Johnson M: Chronic pain management-can we do better? An interview- based survey in primary care. Curr Med Res Opin 2003, 19:703-706.

56. Smith BH, Elliott AM, Chambers WA, Smith WC, Hannaford PC, Penny K: The impact of chronic pain in the community. Fam Pract 200I, 18:292-299.

\section{Pre-publication history}

The pre-publication history for this paper can be accessed here:

http://www.biomedcentral.com/1471-2458/9/299/pre pub
Publish with Biomed Central and every scientist can read your work free of charge

"BioMed Central will be the most significant development for disseminating the results of biomedical research in our lifetime. "

Sir Paul Nurse, Cancer Research UK

Your research papers will be:

- available free of charge to the entire biomedical community

- peer reviewed and published immediately upon acceptance

- cited in PubMed and archived on PubMed Central

- yours - you keep the copyright
BioMedcentral 